\title{
Distribution of Initial Vegetation Recruitment on Bare Bar in Sand Bed River
}

\author{
Yuexia Zhou*, Yuji Toda*, Eijiro Kubo* \\ Graduate School of Engineering, Nagoya University, Nagoya, Japan

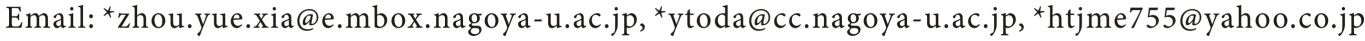

How to cite this paper: Zhou, Y.X., Toda, Y. and Kubo, E. (2018) Distribution of Initial Vegetation Recruitment on Bare Bar in Sand Bed River. Journal of Water Resource and Protection, 10, 441-460. https://doi.org/10.4236/jwarp.2018.104024

Received: March 9, 2018

Accepted: April 27, 2018

Published: April 30, 2018

Copyright $\odot 2018$ by authors and Scientific Research Publishing Inc. This work is licensed under the Creative Commons Attribution International License (CC BY 4.0).

http://creativecommons.org/licenses/by/4.0/ (c) (i) Open Access

\begin{abstract}
Riparian vegetation is known to affect the flood flow and the riparian environment, and it is important for river engineers to know the vegetation dynamics in river. Despite a number of researches have been performed for vegetation dynamics, the mechanism of initial vegetation recruitment is still not clear. In this study, two field surveys by using Unmanned Aerial Vehicle (UAV) remote sensing, UAV aerial photographs analysis and a numerical simulation were conducted to detect the location of initial vegetation recruitment and explore its relationship with hydrology and river morphology. The initial vegetation recruitment was identified by comparing vegetation distributions before and after vegetation germination. Most of the initial vegetation recruitment locations were found either along dunes on sandbar or along the wet/dry rotational area of shore bank. Results of the aerial photographs analysis showed that the initial vegetation recruitment occurred at the downstream side of crest of dunes. As for the vegetation recruitment zone located along shore bank, the relative elevation of different recruitment zones is almost same, and the mean value of the relative elevation is around $0.33 \mathrm{~m}$. With the comparison of the contour map of river morphology and the initial vegetation recruitment zone, the shape of initial vegetation recruitment zone is positively consistent with the shape of river morphology distribution. The results of numerical analysis show that the initial vegetation recruitment zone located along shore bank experienced intermediate flood pulse. The inundation frequencies during seed dispersal and germination period for the internal and external boundaries of vegetation recruitment zone are $23.87 \%$ and $6.2 \%$, respectively.
\end{abstract}

\section{Keywords}

Initial Vegetation Recruitment, UAV Remote Sensing, Downstream Side of Dune, Relative Elevation, Inundation Frequency 


\section{Introduction}

Riparian vegetation zone is a complex ecotone, which connects water body to upland vegetation, and this ecotone can be affected by high water table and soil water retention ability [1]. Riparian vegetation is one significant component of ecosystem for transporting organic materials and nutrients for the surrounding soil [2]. However, riparian vegetation has obvious dynamics in recent years with the disturbances of anthropogenic action and natural effect [3], and dynamics of riparian vegetation can affect flood management and ecological balance [4] [5] [6]. Vegetation recruitment is the preliminary stage for riparian vegetation dynamics, and it experiences seed dispersal, germination, seedling survival and establishment. Once the riparian vegetation was established, it has been known to affect not only river hydrology, such as river flow velocity and water depth, by changing flow resistance [7] [8], but also river morphology, such as river bed elevation and transaction, by changing sediment deposition and degradation [4] [9]. Bank vegetation can resist the erosion of river bank during floods, which resulted in deeper river channel depth and narrower water channel width [10] [11] [12]. The decrease of water channel width provide much more stable habitat for riparian vegetation, and this means vegetation recruitment and river morphology are interacted [5]. Study on the effect of hydrology and morphology to vegetation recruitment was also proposed by many researchers.

Location of vegetation recruitment zone is closely related to hydrological processes and morphological variables. Hydrological variables, such as flood pulse, are regarded as one dominant driving force for vegetation recruitment, growth and destruction with its effect on controlling the entrance, permanence of water flow and nutrient [13] [14]. Moreover, flood pulse can be recognized by flood inundation, flood frequency, flood recurrence and flood amplitude, which may be utilized as connectivity parameters to express the relationship between a dominant variable (e.g. flood pulse) and its dependent ones (e.g. riparian vegetation) [15]. [14] found that flow frequency acts strongly on the dynamics of riparian vegetation dynamics, and pointed out that species recruitment occurs under the condition of low water level and high recurrence flows, with a recurrence average of 69 days in the grass-herbaceous lower floodplain. Flood regimes of the dry season and the wet season are main regulator of the vegetation cover [16]. The seeds of the Parana River's riparian can germinate at the rotation between dry and low water level [17]. Furthermore, river morphology can also influence the spatial distribution and generation probability of vegetation recruitment zone. [18] found that woody vegetation may recruit at the area containing moist soil and depth of ground water at plots is within the moist soil zone. [19] stated that vegetation can recruit along streams with finer substrate, and more gradual stage fluctuations are necessary for larger rivers. Seed germination is one extreme complicated process, which is always related to temperature, oxygen, light and some other physical conditions [20]. Vegetation germination rate is also affected by the moisture condition of the initial recruitment Zone [21], 
which is determined by the diameter and composition of sediment and the groundwater table.

These studies referred above have advanced our understanding of the fundamental factors to initial vegetation recruitment. Flood frequency and physical condition of the study sites are significant predicator for the initial vegetation recruitment. However, they mainly focus on the specific factors analysis, such as soil water content and substrate composition, study on vegetation recruitment from a reach scale is not enough. Investigation of vegetation recruitment from a large reach scale can provide us more direct understanding on the vegetation recruitment in the actual rivers. And these studies on the initial vegetation recruitment were focused on the river margin; however, more detail investigation of the potential initial vegetation recruitment on bare bar in sand bed river should be further clarified.

As location and spatial distribution of vegetation recruitment can impact hydrology and river morphology, and vegetation can also affect the river channel management. Therefore, further study on the mechanism of vegetation recruitment, especially from the reach scale range, is significant. In this study, one sand-river (Suzuka River) was selected as target research site to explore vegetation recruitment condition. The investigation and analysis on the initial vegetation recruitment, including seed dispersal and germination, were conducted. Firstly, reach scale field survey by using UAV remote sensing was employed to investigate the vegetation distribution, river flow condition and river morphology. Secondly, UAV aerial photographs, including orthomosaic and digital elevation model (DEM), were utilized to analyze the location of initial vegetation recruitment and its conjunction with river morphology. Finally, the method of numerical simulation was performed for investigating the correlativity between initial vegetation recruitment zone, hydrology and river morphology.

\section{Methods}

\subsection{Study Site}

Suzuka River is located at the north of Mie prefecture, Japan, the total length of its main channel is almost $38 \mathrm{~km}$, and its basin area is $323 \mathrm{~km}^{2}$. The vegetation expansion has become one serious problem at Suzuka River in recent years.

Field survey area of this study was the main river channel, derived from 14.9 $\mathrm{km}$ to $9.8 \mathrm{~km}$ from river mouth. Slope of river bed of this study area is approximately $1 / 627$, the sediment diameter of river bed material is mainly between 1.0 $\mathrm{mm}$ to $10 \mathrm{~mm}$, and the representative sediment diameter is $5.6 \mathrm{~mm}$. The main hydraulic structures in the study area, which can change river flow regime and river morphology, are two fixed weirs located at $9.6 \mathrm{~km}+175.0 \mathrm{~m}$ and $13.4 \mathrm{~km}+$ $120.0 \mathrm{~m}$ upstream from the estuary of Suzuka River, respectively. The dominant types of woody vegetation on floodplain are Simon bamboo, Celtissinensis and willow, and the typical herbaceous vegetation at the margin of sandbar and river bank is Phragmites japonica. The hydrological data about Suzuka River, for ex- 
ample, water level, discharge and some other hydrological data are collected from the measured results at the gauging stations, such as Takaoka gauging station.

The study area, the location, the basin and stream branch of Suzuka River are shown in Figure 1.

\subsection{Definitions}

Dune slope is determined by the rates of change of the surface in the horizontal $(\mathrm{d} z / \mathrm{d} x)$ and vertical $(\mathrm{d} z / \mathrm{d} y)$ directions from the center cell. And the basic algorithm used to calculate the slope in unites of degree $\left(\right.$ Slope $\left._{\mathrm{d}}\right)$ is shown as formula (1).

$$
\text { Slope }_{\mathrm{d}}=\operatorname{ATAN}_{\sqrt{\left([\mathrm{d} z / \mathrm{d} x]^{2}+[\mathrm{d} z / \mathrm{d} y]^{2}\right)}} *(180 / \pi)
$$

Inundation frequency during initial vegetation recruitment period is the inundation probability of a point on the bottomland is submerged. And the algorithm used to calculate the inundation frequency is defined as formula (2).

$$
P_{\text {inu }}=T_{\text {inu }} / T_{\text {total }} \times 100 \%
$$

where, $T_{\text {inu }}$ is the inundation period of a point.

$T_{\text {total }}$ is the total period during initial vegetation recruitment.

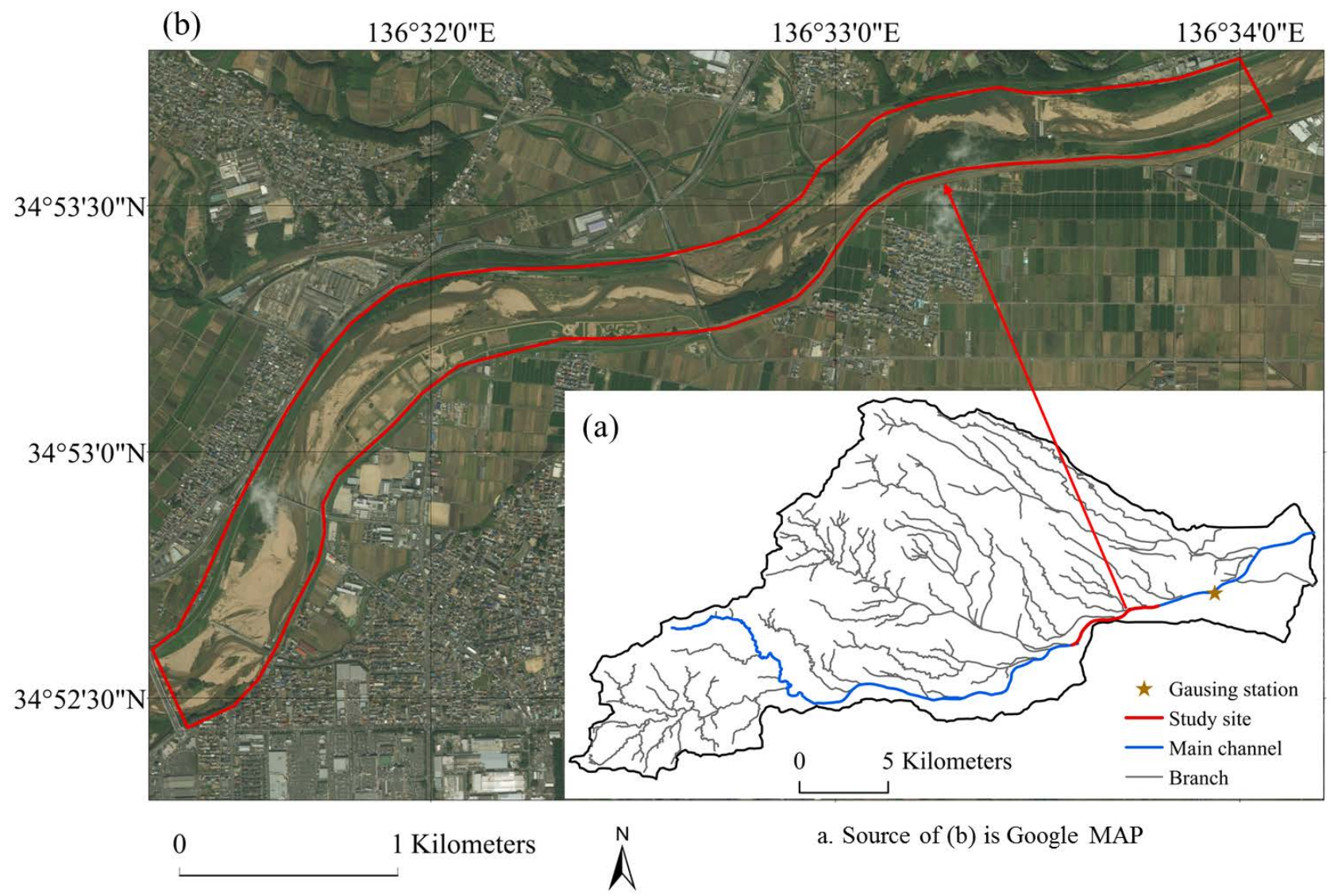

Figure 1. Water level gauging station, study site, stream network and location of Suzuka River basinin Japan. 
Internal boundary and external boundary are the location of the lowest and highest elevation of the initial vegetation recruitment zone. Relative elevation is the vertical distance between the external boundary of initial vegetation recruitment zone and ordinary river flow.

\subsection{Field Survey by Using UAV Remote Sensing}

Field survey in river by ground-based observation was popularly used in the previous hydrological and ecological studies [22] [23]. However, the ground-based observation has a limitation in the resolution and accuracy of data in time and space. Since the ecological processes of seed dispersal, seed germination are relative short and river morphology alteration during this period is small, high accuracy and resolution Digital Surface Model (DSM) are vital for the study. For conducting large scale investigation with high resolution and accuracy, some new field investigation methods are necessary. UAV, with the characteristic of collecting information without physical contact and high resolution of photographs, is regarded to be an effective and convenient field study tool [24] [25].

It was reported that seed dispersal occurs at the falling limb of hydrography after relative large flood [19], and seed germination and seedling growth are influenced by the spring river flow [26]. To refer these previous study results, the field survey by using UAV was conducted at October, 2016 and May, 2017, respectively, since most of the relative large typhoon and flood occur at August or September in Japan.

Specific procedures of the field survey by using UAV are outlined as Figure 2. UAV used in this study was DJI PHANTOM 3 ADVANCED.

Agisoft Photoscan Professional edition was employed for disposing UAV images. With the reason of the artificial error for setting image overlap and the refractive effect of water [27], the distortion of river morphology is one general problem in UAV field survey. To revise coordinate and digital elevation model (DEM) data, the ground control points (GCPs) are imperative. The GCPs in the present survey were selected on road and embankment, and 36 and 40 GCPs were set for the field survey of October, 2016 and May, 2017, respectively.

UAV aerial photographs, acquiring from UAV images disposing results, were

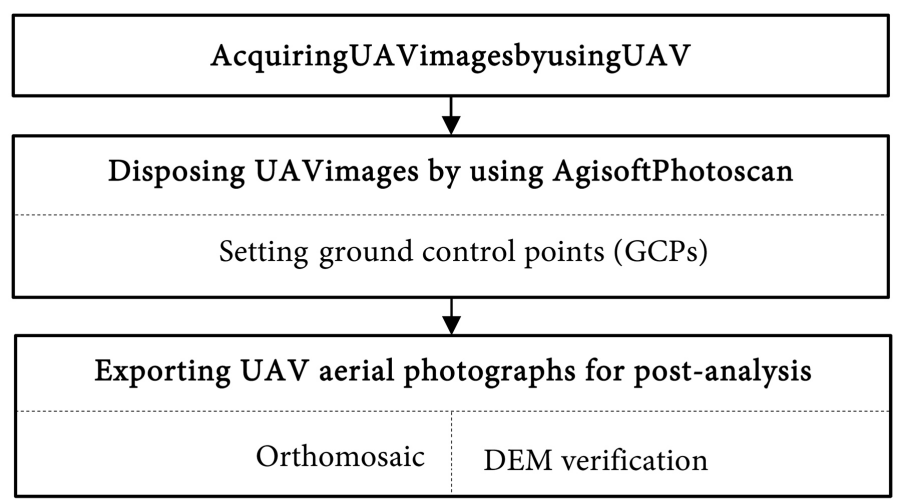

Figure 2. Procedures of field survey by using UAV. 
exported from Agisoft Photoscan, and they were employed for the post analysis. UAV aerial photographs, including, Orthomosaic (Red, Green, Blue (RGB)) and DEM, were mainly used to identify the location of initial vegetation recruitment area and to detect river morphology, respectively. Although GCPs were set during the establishment of DEM, the further verification of the disposed result can provide reliable results of the post analysis. Here, two methods were utilized for the verification of DEM. The first method was to compare the river slope between the UAV field survey and the data measured by government (0.0016). The result is shown in Figure 3(a), and the agreement is quite well. The second method was to choose 14 points along the field survey area, and compare the elevation of these points between the field survey result and the actual value, the mean error and root-mean-square error are 0.288 and 0.381 , respectively (Figure $3(\mathrm{~b})$ ), and these errors can be acceptable level of the accuracy required for the post analysis.

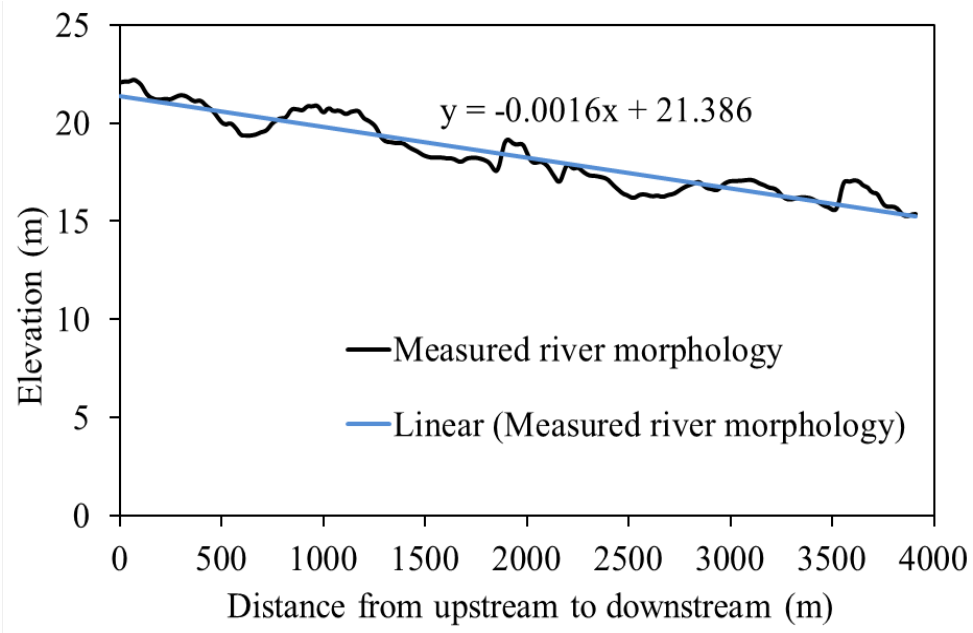

(a)

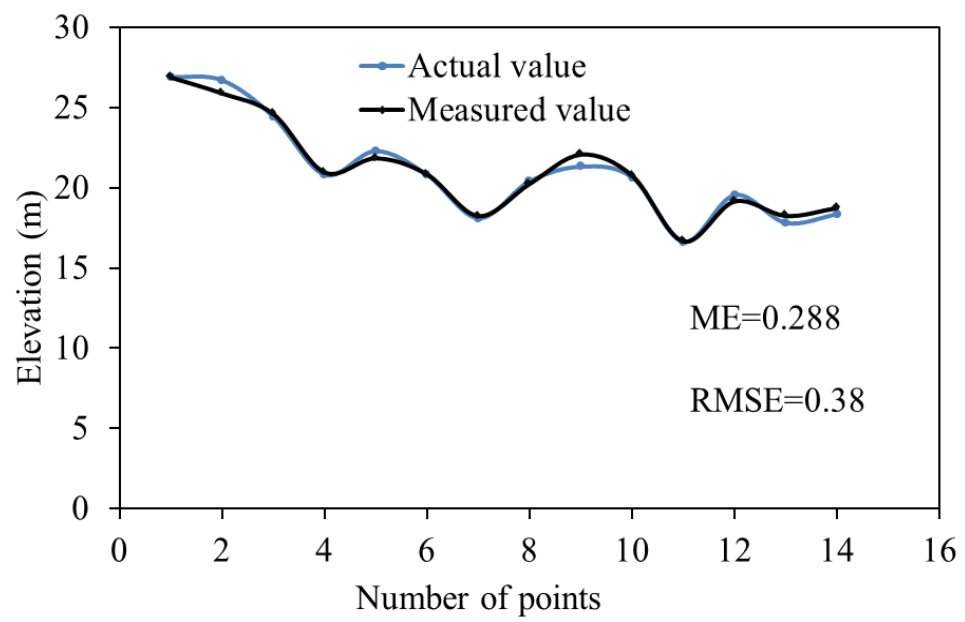

(b)

Figure 3. DEM verification, (a) comparison of river slope, (b) comparison of actual and measured value. 


\subsection{UAV Aerial Photographs Analysis by ArcGIS}

ArcGIS was employed to detect the spatial characteristics of land cover features. Since the difference of RGB code between water and artificial area was often unclear, the manual estimation was carried out for extracting the boundary of these areas in this study. Maximum Likelihood Classification (MLC) was then utilized for the classification of vegetation distribution and sandbar area. With the comparison of vegetation distribution area between the two field surveys, the initial vegetation recruitment area was extracted. Morphology of the initial riparian vegetation recruitment zone was further studied in the spatial analysis of ArcGIS, and this is performed for discussing the relationship between river morphology and initial vegetation recruitment zone.

\subsection{Methods of Numerical Analysis}

The location and spatial distribution of initial vegetation recruitment zone was identified from the results of UAV aerial photographs analysis. A numerical simulation was conducted to further clarify the relation of the location of vegetation recruitment zone with hydrology, in which Nays2DH (http://i-ric.org/en/), with the function of depth averaged 2 dimensional flow and bed morph-dynamics, was employed. The processes of numerical simulation are depicted as Figure 4.

DEM data, obtained from UAV remote sensing, was imported as the river geomorphology. For the inflow discharge condition, the daily discharge (Figure 5) during the field survey period was calculated from water level, which was collected at Takaoka gauging station (Figure 1). The dimeter of the bed material was set as $1.8 \mathrm{~mm}$, and Manning coefficient was set as 0.03 . The water submerged zone of low-water channel under different discharges was estimated from the numerical simulation. Water depth and inundation frequency were further analyzed for detecting the hydrological condition of the potential initial vegetation recruitment zone.

\section{Results}

\subsection{Results of UAV Aerial Photographs Analysis}

The initial recruitment zones found at the second field survey (May, 2017) are

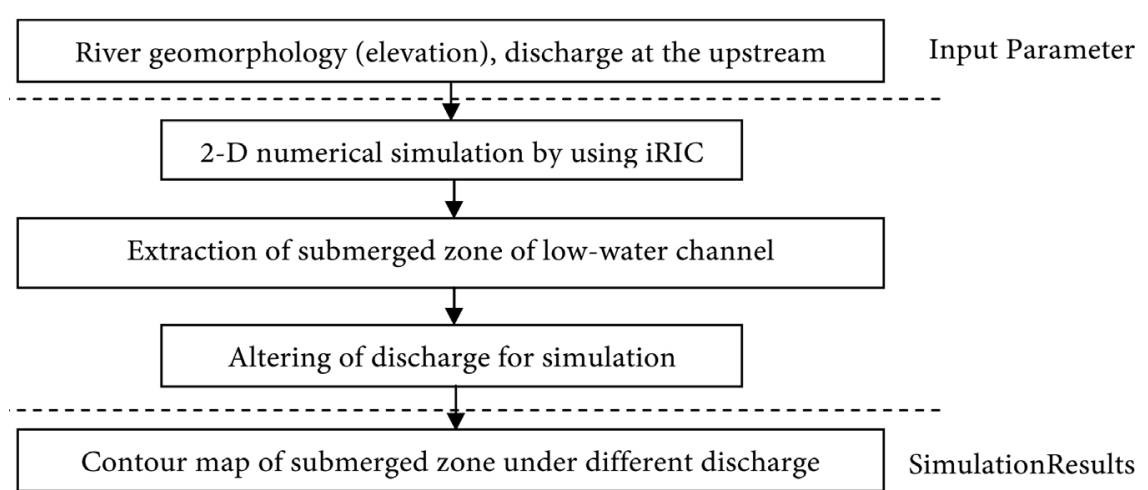

Figure 4. Simulation flowchart of water submerged zone. 
shown in Figure 6. It was found that there are two kinds of vegetation initial recruitment zones, one is on the bare bar far away from shore bank, and another one is close to the shore bank. Therefore, the initial vegetation recruitment zones were classified into two types based on their distance from river flow. The zones at Position-S1 to Position-S6 are the zones of initial vegetation recruitment distributed along shore bank, and the zones at Position-D1 to Position-D3 are the zones of initial vegetation recruitment far away from shore bank, and they distributed along dunes on bare bar. The specific characteristics of the two types of initial vegetation recruitment were stated as followings.

\subsubsection{Initial Vegetation Recruitment at Dunes on Sandbar}

Figure 7(a) shows that the orthomosaic of sandbar (Oct., 2016), Figure 7(b) shows the slope of sandbar, and Figure 7(c) shows the orthomosaic of sandbar (May, 2017), which located at Position-D3 (Figure 6). Figure 7(b) shows that the zone with high relative slope is the location of dune. Figure $7(\mathrm{c})$ shows that there is initial vegetation (green color zones) recruit on the bare bar, and the

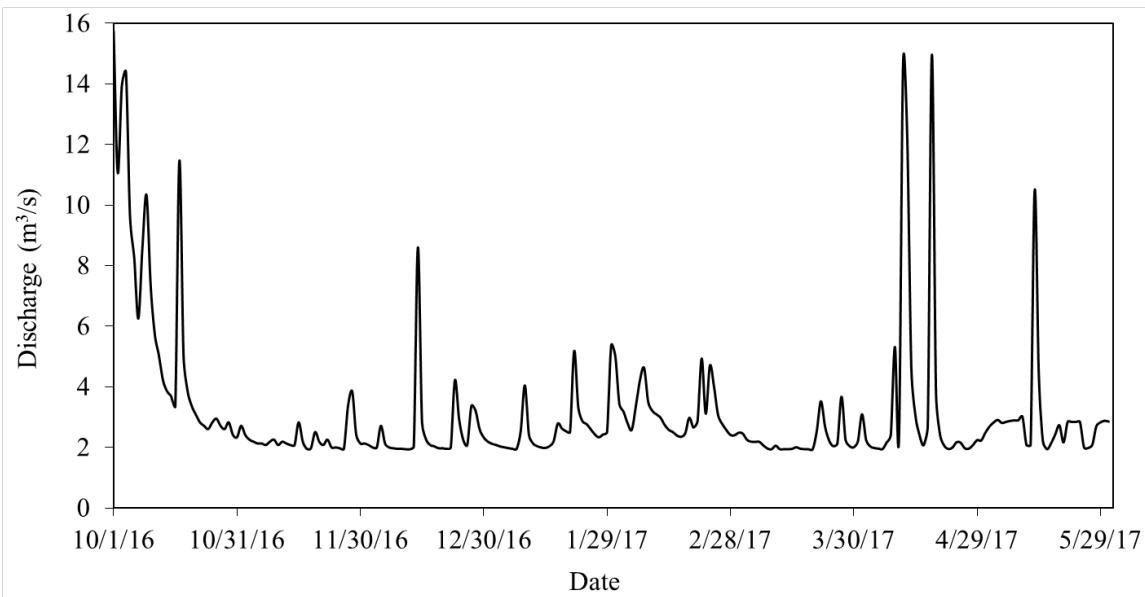

Figure 5. Daily discharge at Takaoka gauging station during field survey period.

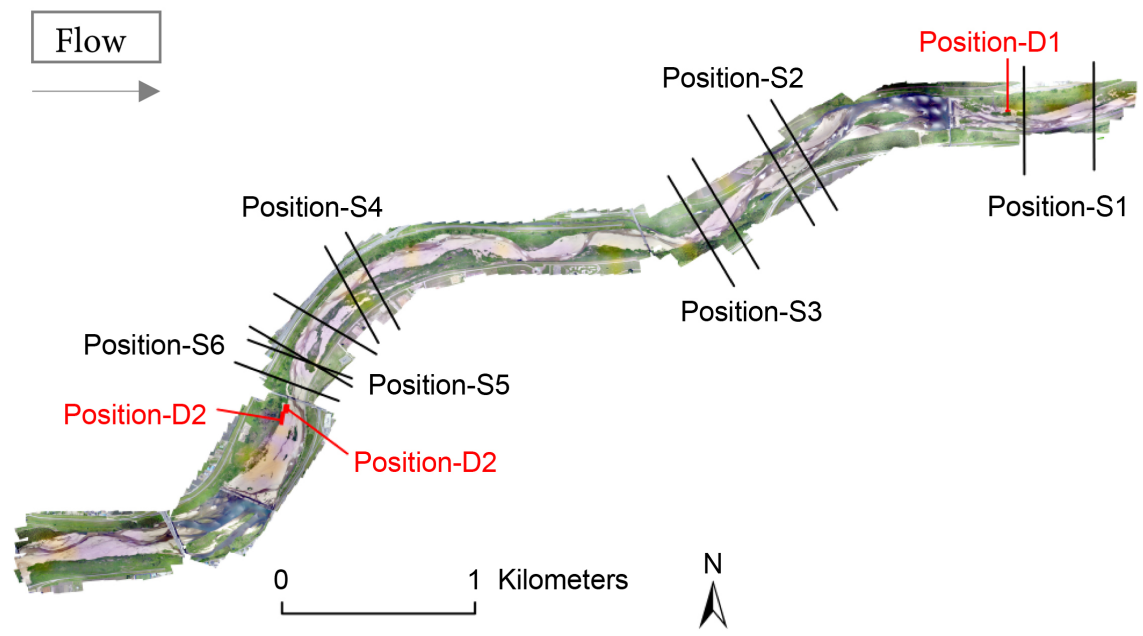

Figure 6. Position of vegetation recruitment zones. 


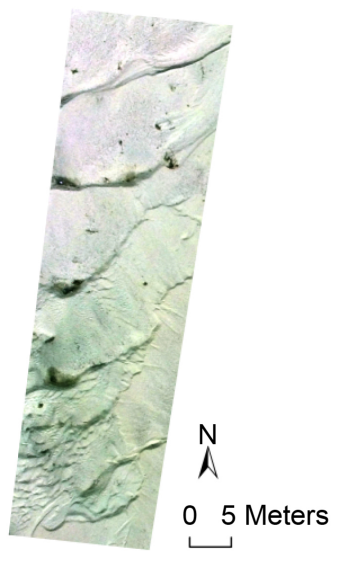

(a)

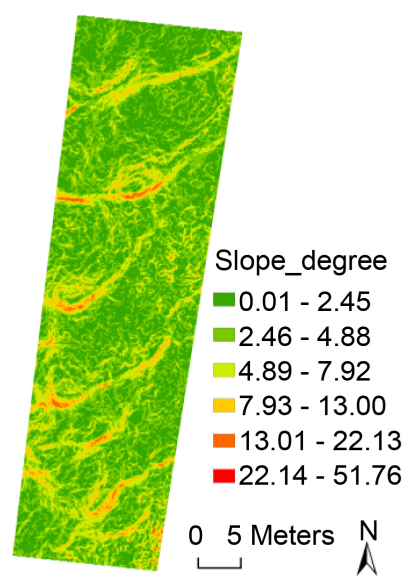

(b)

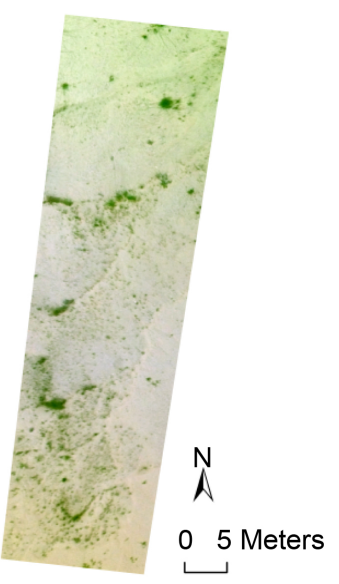

(c)

Figure 7. Orthomosaicof dune (Oct., 2016), (b) The slope of sandbar, and (c) Orthomosaicof dune (May, 2017).

initial vegetation recruitment zone distributes at the dunes on bare bar is identified with the comparison of Figure 7(a) and Figure 7(b). The initial vegetation recruitment at dunes on bare bar can also be found at Position-D1 and Position-D2. The distribution of initial vegetation recruitment at Position-D1 and Position-D2 were analyzed as followings.

Figure 8(a) and Figure 8(b) show that the vegetation distribution of Position-D1 at October, 2016 and May, 2017, respectively, and Figure 9(a) and Figure 9(b) show those of Position-D2. Comparing the bare bar area of Position-D1 and Position-D2 between the two fields' surveys, initial vegetation (green color zones) recruit at the dunes of bare bar was also identified, which is similar to Position-D3.

\subsubsection{Dune Morphology and Initial Vegetation Recruitment Zone at Dunes}

One longitudinal cross section was extracted to analyze the relationship between dune morphology and location of initial vegetation recruitment zone. Figure 10(a) shows the morphology of sandbar at Position-D1 on sandbar, and Figure

10(b) shows the longitudinal cross section of red line in Figure 10(a). The initial vegetation recruitment zone was found to concentrate at the downstream side of crest of dunes (Figure 10(b)). Figure 11(a) and Figure 11(b) show the morphology and the longitudinal cross section at Position-D2, in which the initial vegetation recruitment zones were also found at the downstream side of crest of dunes.

\subsubsection{Initial Vegetation Recruitment along Shore Bank}

The land cover located at Position-S1 (Figure 6) was classified into vegetation, sandbar, artificial and water area, as shown in Figure 12, and Figure 12(a) and Figure 12(b) show that the land cover classification of the field survey at Oct., 2016 and May, 2017, respectively. The initial vegetation recruitment zone 


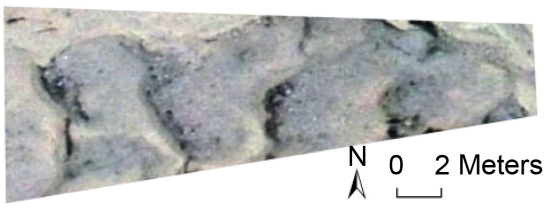

(a)

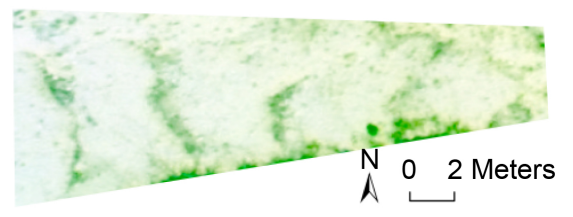

(b)

Figure 8. Comparison of vegetation distribution between the two field surveys, orthomosaic of dune at Position-D1 (a) Oct., 2016, (b) May, 2017.

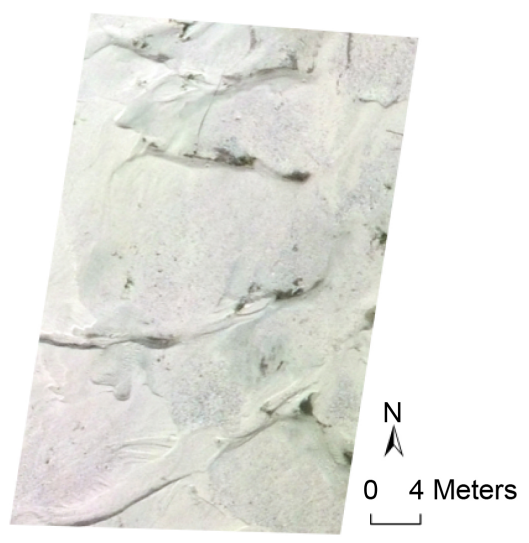

(a)

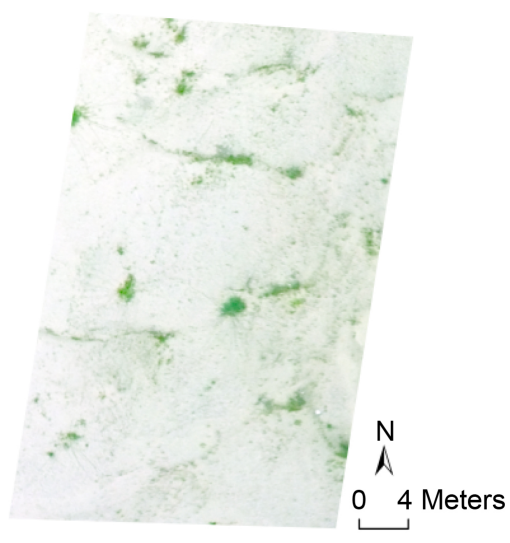

(b)

Figure 9. Comparison of vegetation distribution between the two field surveys, orthomosaic of dune at Position-D2 (a) Oct., 2016, (b) May, 2017.

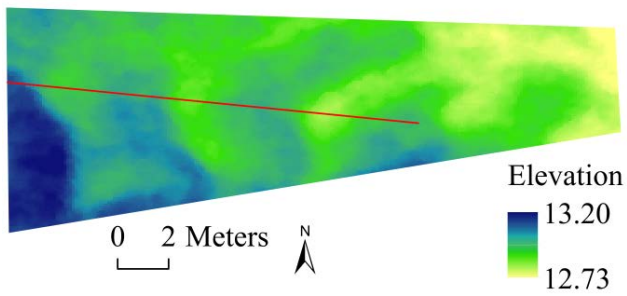

(a)

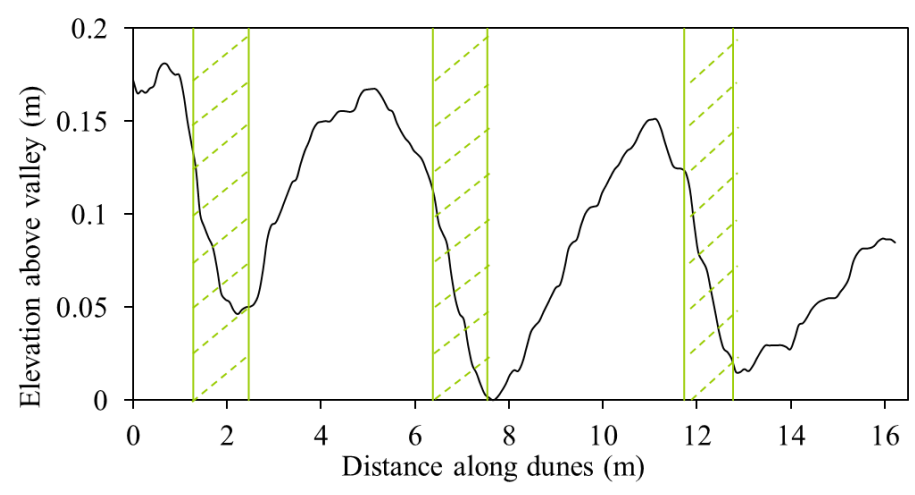

(b)

Figure 10. (a) Morphology of dune, (b) Longitudinal cross section of dune (location of red line), and zone between the green lines indicates initial vegetation recruitment zone. 


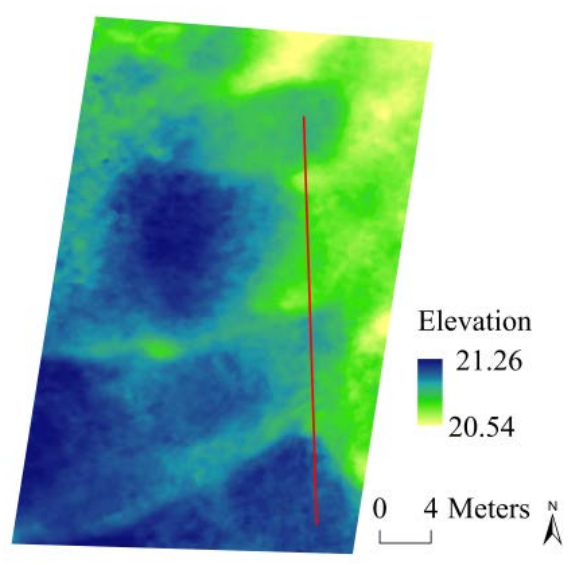

(a)

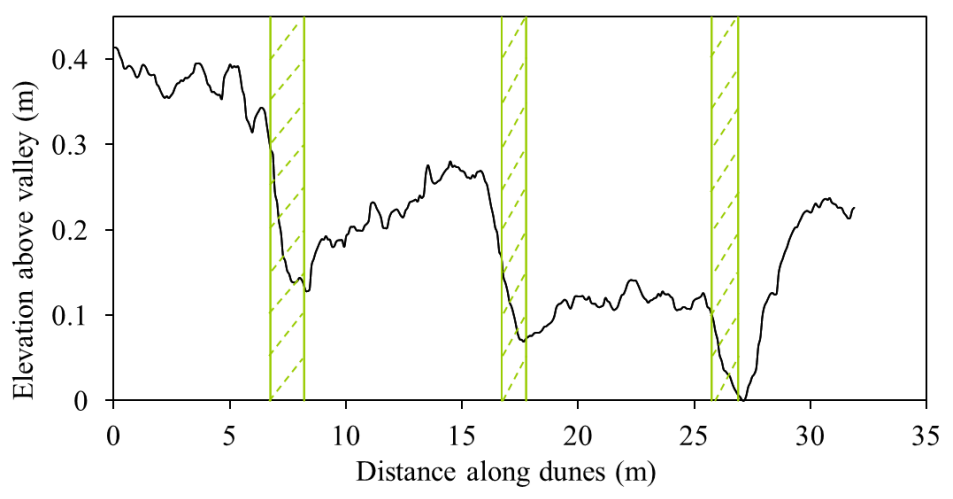

(b)

Figure 11. (a) Morphology of dune, (b) Longitudinal cross section of dune (location of red line), and zone between the green lines indicates initial vegetation recruitment zone.

(marked with light green) along shore bank was identified with the comparison between Figure 12(a) and Figure 12(b). The similar analysis was also applied at Position-S2, and the results are shown in Figure 13(a) and Figure 13(b). Figure 12(b) and Figure 13(b) show that the initial vegetation recruitment had the characteristics of approximately paralleling to shoreline and scattered distribution, respectively.

\subsubsection{River Morphology and Initial Vegetation Recruitment Zones along Shore Bank}

The quantitative relationship between the initial vegetation recruitment zone and river morphology was explored by comparing distribution of the recruitment zone and the contour map of river morphology. Figure 14(a) and Figure 14(b) show that the river morphology and contour line value around the initial vegetation recruitment zone. Figure 14(a) shows that initial vegetation recruitment zone at Position-S1 located at the elevation between $11.95 \mathrm{~m}$ and $12.20 \mathrm{~m}$. The zone between this two elevation intervals was almost parallel to shoreline, and this was positively consistent with the shape of initial vegetation recruitment zone at Position-S1. Figure 14(b) shows that initial vegetation recruitment zone 


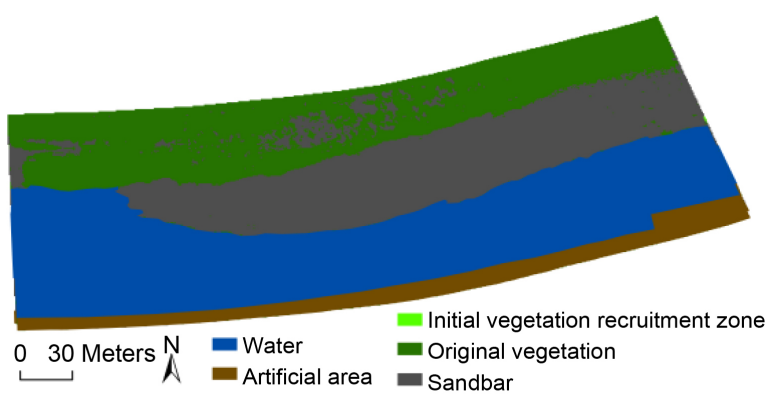

(a)

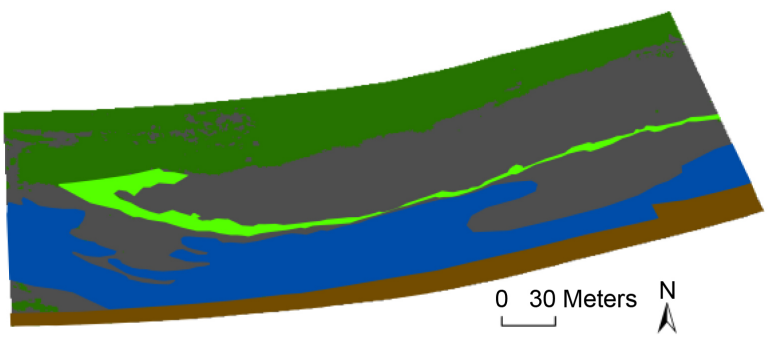

(b)

Figure 12. Land cover classification at Postion-S1 (a) Oct., 2016), (b) May, 2017.

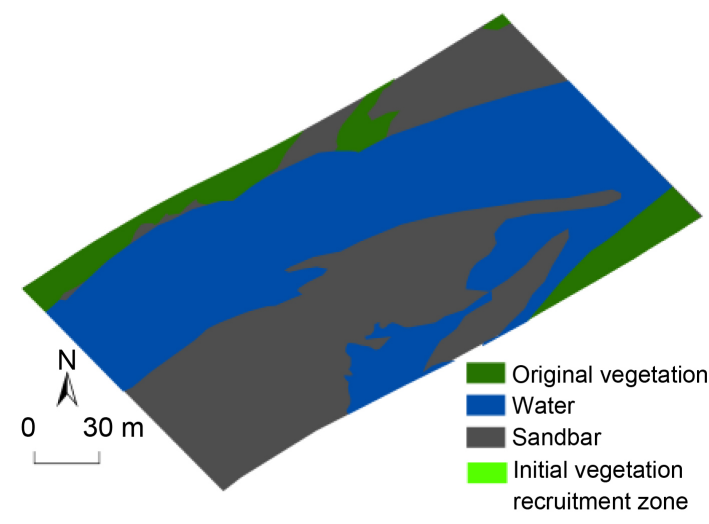

(a)

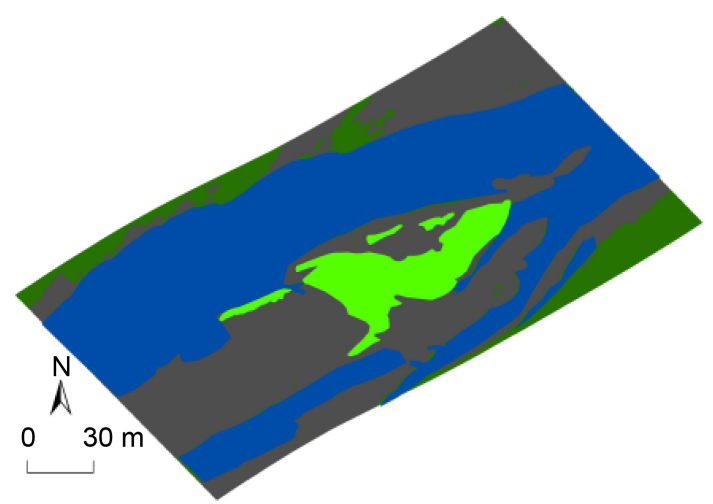

(b)

Figure 13. Land cover classification at Postion-S2 (a) Oct. 2016, (b) May, 2017. 


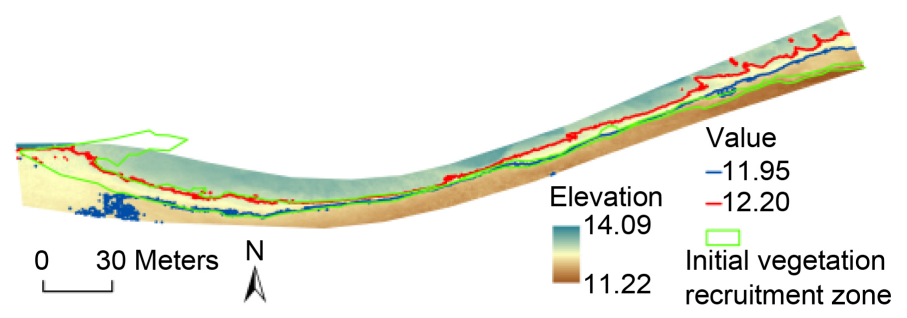

(a)

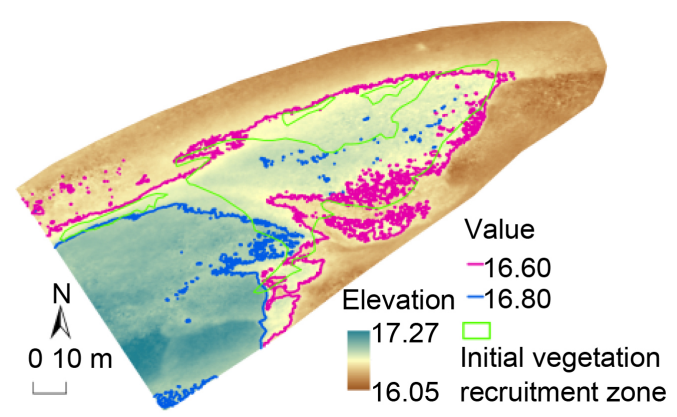

(b)

Figure 14. Contour map of river morphology near vegetation recruitment zone at (a) Position-S1 and (b) Postion-S2.

at Position-S2 located at the elevation between $16.60 \mathrm{~m}$ and $16.80 \mathrm{~m}$. The zone between this two elevation intervals had scattered distribution, and this was also posotively consistent with the shape of initial vegetation recruitment zone at Position-S2. Therefore, spatial distribution and shape of initial vegetation recruitment were tightly influenced by river morphology.

\subsection{Results of Numerical Simulation}

Figure 15 shows that the contour map of submerged zone under different discharges and the corresponding submerged discharge of the initial vegetation recruitment zone for internal boundary and external boundary is $3.0 \mathrm{~m}^{3} / \mathrm{s}$ and 7.0 $\mathrm{m}^{3} / \mathrm{s}$, respectively. Taking the ordinary river flow as the original point, and one cross section, which is vertical to shoreline, was elected to analyze the water depth and inundation frequency. Figure 16 shows water depth along cross section 1 , and the initial vegetation recruitment zone was non-submerged when discharge under $3.0 \mathrm{~m}^{3} / \mathrm{s}$, and the initial vegetation recruitment zone was submerged when discharge reaches or exceeds $7.0 \mathrm{~m}^{3} / \mathrm{s}$. This means that the initial vegetation recruitment zone was under the condition of wet/dry rotation. Figure 17 shows that the inundation frequency for the internal and external boundary of initial vegetation recruitment zone is $23.87 \%$ and $6.20 \%$, respectively.

\section{Discussion}

The results of UAV remote sensing, UAV aerial photographs analysis and numerical simulation explained that that river morphology and hydrology are crucial factors for the distribution of initial vegetation recruitment zone. The tight 


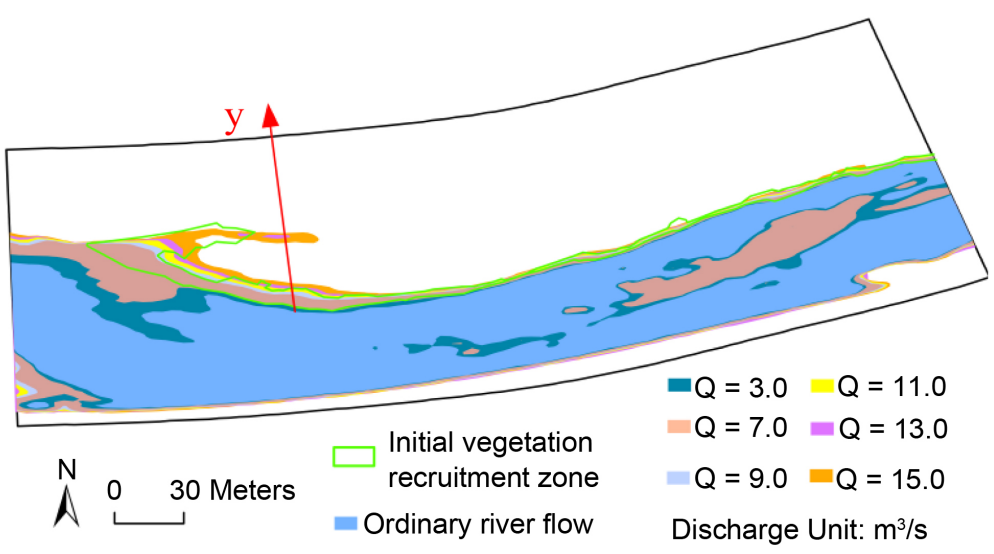

Figure 15. Contour map of submerged zone.

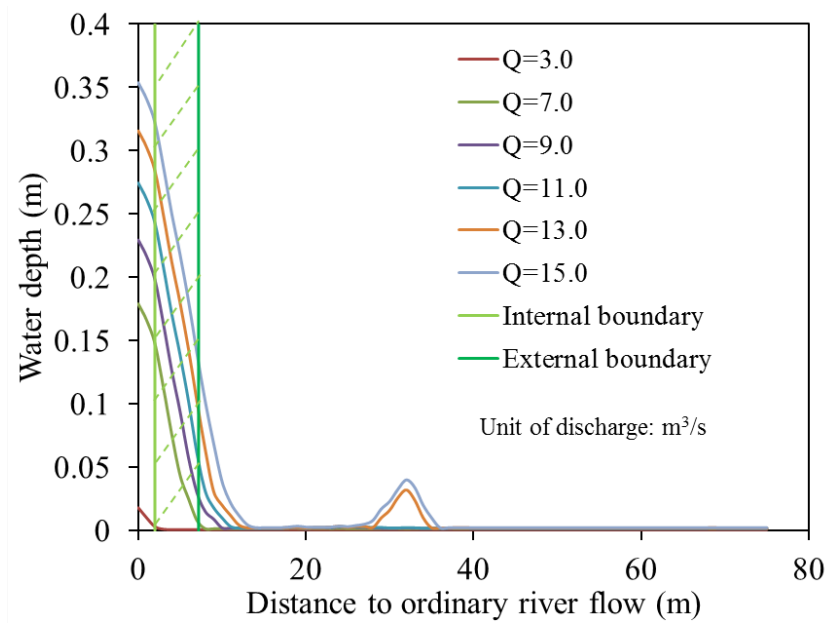

Figure 16. Water depth of cross section 1 (at y direction in Figure 15).

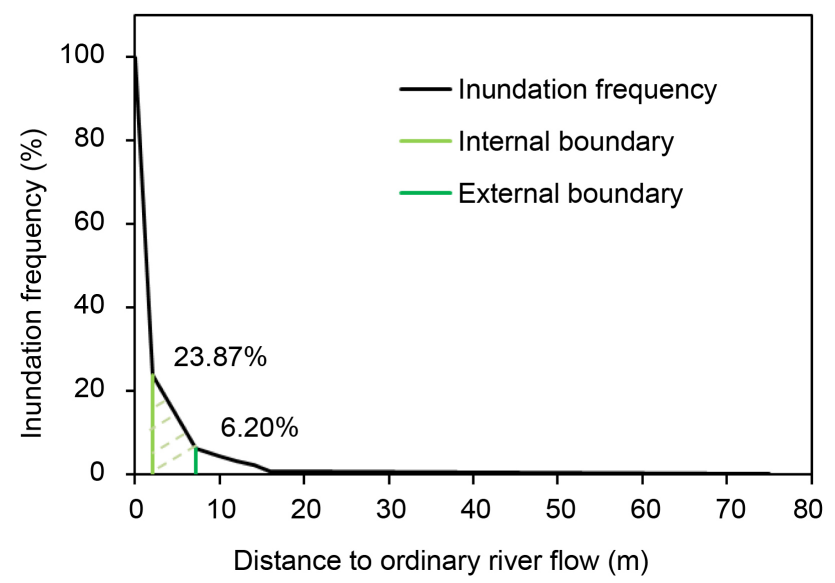

Figure 17. Inundation frequency of initial recruitment zone (at $y$ direction in Figure 15).

relationship between hydro-geomorphological variables and ecological features is clearly showed in this paper. 


\subsection{Initial Vegetation Recruitment and River Morphology}

The results of aerial photographs analysis indicated that initial vegetation recruitment located either behind the crest of dunes on sandbar or along shore bank, and they also show that the shape and range of initial vegetation recruitment zone were closely related to the dune morphology and the relative elevation from ordinary river flow.

\subsubsection{Initial Vegetation Recruitment and Dune Morphology}

Figure 10(b) and Figure 11(b) show the initial vegetation recruitment zone concentrated at the downstream side of crest of dunes, and this phenomenon may be explained from the following two aspects.

Firstly, seed bank may be larger at the downstream side of dune. The reason is that during the flood period, the flow separation from the crest of dunes can promote seed, which dispersed by hydrochory, to be stranded at the downstream side of dunes on sandbar. Therefore, compared with upstream side of dunes, seed bank is more plenty at downstream side of dunes. Secondly, the nutrient and water content may be abundant at the downstream side of dune. The possible reasons for the abundant nutrient and water content at the downstream side of dunes have reported by many researchers. [28] found that fine sand filled at the trough by using the method of numerical simulation and field survey. [29] found that $17 \%$ of suspended-load deposited at the downstream side of dune before it reached trough. Therefore, the nutrient and water content at the downstream side of dune increases with the deposition of fine sediment, which can promote seed germination and seedling growth. From both the ecological and hydrological viewpoints, the downstream side of the dunes provides a favorable condition for initial vegetation recruitment.

\subsubsection{Initial Vegetation Recruitment and Relative Elevation}

Vegetation recruitment zone at Position-S1 and Position-S2 show that it located near shore bank and concentrated within two elevation intervals. In this study, we can simplify the low-water channel to express the range of vegetation recruitment zone and its relative position with river flow, as shown in Figure 18. The elevation of vegetation recruitment zone at the other positions along shore bank was also analyzed by comparing the recruitment zone and river morphology. The elevation and relative elevation of each initial vegetation recruitment

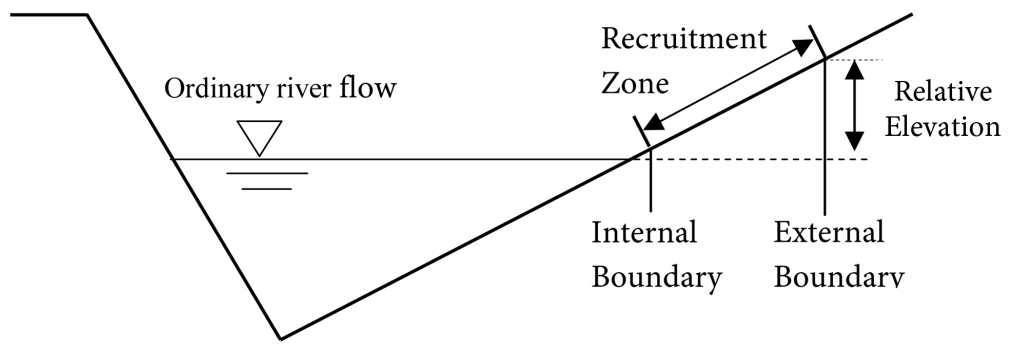

Figure 18. Simplified cross section of low-water channel. 
zone and ordinary river flow are showed in Table 1.

The potential factors for the initial vegetation recruitment along shore bank can be explained as follows. The boundary of recruitment zone is expected to be determined by flow magnitude [19]. The largest daily discharge during field survey period was $15 \mathrm{~m}^{3} / \mathrm{s}$, which was much smaller than annual peak flow, and this provide the possibility for vegetation to recruit along shore bank. Seedling recruitment zone along river margins is limited and controlled, and the highest elevation is mainly determined by the drought stress and the lowest elevation is mainly determined by the scouring stress [30]. With the considerations of inundation period and drought force [30], the external boundary of the initial vegetation recruitment zone cannot prolong too much higher from ordinary flow surface. With the considerations of scoring force and vegetation growth habit [20] [30], the internal boundary of the vegetation recruitment zone has a small relative elevation above ordinary river flow.

Table 1 shows that relative elevation of initial vegetation recruitment to ordinary river flow at different recruitment zones is almost same. The mean value of the relative elevation to ordinary river flow of six recruitment zones (located along shore bank) is $0.33 \mathrm{~m}$. [19] also pointed that the floating seeds deposited along the stream edge and deposited in bands of constant elevation, and then favoring the bands distribution of seedlings.

The previous relative studies also reported the similar results, [31] conducted the field survey of tree recruitment, and he monitored the tree seedling and measured elevation by surveyor's transit and rod. The result showed that the relative elevation (suitable for vegetation recruitment) between low water level and the lower vegetated zone is $0.5 \mathrm{~m}$. [32] concluded that the successful seedlings were generally established at elevations from $80 \mathrm{~cm}$ to $120 \mathrm{~cm}$ above the late summer stream stage. [33] utilized VRS-GPS (almost 1200 points) to investigate sandbar morphology, and the investigation of vegetation was conducted too. His field survey result showed that the mean relative elevation (elevation between water level and vegetation recruitment zone) for annual vegetation recruitment near shore bank is $0.5 \mathrm{~m}$. Therefore, relative elevation between ordinary river

Table 1. Relative elevation of initial vegetation recruitment zones.

\begin{tabular}{ccccc}
\hline $\begin{array}{c}\text { Segment } \\
\text { No. }\end{array}$ & $\begin{array}{c}E_{\text {ordinary }} \\
(\mathrm{m})\end{array}$ & $\begin{array}{c}E_{\text {in }} \\
(\mathrm{m})\end{array}$ & $\begin{array}{c}E_{\text {ex }} \\
(\mathrm{m})\end{array}$ & $\begin{array}{c}\text { Relative } \\
\text { elevation }(\mathrm{m})\end{array}$ \\
\hline 1 & 11.90 & 11.95 & 12.20 & 0.30 \\
2 & 16.50 & 16.60 & 16.80 & 0.30 \\
3 & 16.45 & 16.60 & 16.80 & 0.35 \\
4 & 19.20 & 19.45 & 19.65 & 0.45 \\
5 & 19.40 & 19.50 & 19.70 & 0.30 \\
6 & 19.35 & 19.45 & 19.65 & 0.30 \\
\hline
\end{tabular}

a. $E_{\text {ordinary }}, E_{\text {in }}$ and $E_{\text {ex }}$ mean the elevation of ordinary river flow, elevation of internal and external boundary of the vegetation recruitment zone. b. Segment No.1 to 6 was corresponding with the Position-S1 to S6. 
flow and boundary of initial recruitment zone is thought to be one important factor for deciding the spatial distribution of vegetation recruitment zone.

Although our conclusion is similar to the previous studies, this study provides the possibility of using UAV remote sensing. Since VRS-GPS needs artificial points setting and operation, investigation accuracy may be affected by the limitation of point's number and human sample error. However, UAV is controlled by GPS, and setting of more investigation points is feasible. Therefore, field survey by using UAV provides us the possibility to analyze vegetation recruitment in a relative accurate and wide range viewpoint.

In this study, relative elevation of recruitment zone at segment 4 is $0.45 \mathrm{~m}$, which is bigger than other segments. The possible reason is that vegetation recruitment zone at this segment is near to the existed vegetation; therefore, seed source at this segment may be different from other segments.

\subsection{Initial Vegetation Recruitment and Hydrology}

The simulation results show that the vegetation recruitment appeared at the wet/dry rotational area near shore bank. This result indicates that it is impossible for vegetation to recruit at those places with everlasting river flow or with permanent droughty condition. The period of inundation can not only contribute to decrease the mortality caused by drought, but also can facilitate the formation of fresh substrate, which contains much more fine sediment and nutrient [6]. The period of non-inundation can provide the possibility for seed or seedling to contact with light and oxygen, which are dominant factors for vegetation recruitment. This paper utilizes inundation frequency to express the effect of flood pulse on vegetation recruitment, and the inundation frequency of the internal and external boundary of the initial vegetation recruitment zone is $23.87 \%$ and $6.20 \%$, respectively. This result implies the intermediate inundation frequency may promote vegetation recruitment. [34] also reported that frequency of inundation affected community composite. The relation between vegetation distribution and hydrology might also be expressed by other parameters, such as Fluvial Connectivity Quotient (FCQ), which means the ratio between number of flooding days and number of non-flooding days. However, the calculation of FCQ for each site was based on the approximate two years (October 1996 to August 1998) continuous observation, and those required much more time and attention. Time-consuming limits the application of FCQ to large scale river channel.

In this study, numerical simulation was employed to detect the effect of hydrology on vegetation recruitment. The potential hydrological condition (such as inundation frequency) for the initial vegetation recruitment can be easily calculated by comparing the contour map of submerged zone and initial vegetation recruitment zone. Therefore, combination of numerical simulation and UAV remote sensing, UAV aerial photographs analysis may be one effective method to explore the relationship between hydrological variables and ecological features. 


\section{Conclusions}

This study utilized UAV remote sensing to investigate the initial vegetation recruitment zone. High resolution of aerial photographs allowed the possibility for the detailed analysis of vegetation distribution and river morphology, demonstrating the great efficiency and usefulness of UAV remote sensing. Based on the UAV remote sensing, UAV aerial photographs analysis and numerical analysis, characteristics of initial vegetation recruitment zone and its relationship with river morphology and hydrology were summarized as followings.

Initial vegetation recruitment located at either the downstream side of crest of dunes on bare bar or the wet/dry rotational area along shore bank. Relative elevation of initial vegetation recruitment zones along shore bank is almost same, and the shape of vegetation distribution is consistent with river morphology distribution. And the intermediate flood pulse maybe available for the recruitment of initial vegetation.

\section{References}

[1] Naiman, R.J. and Decamps, H. (1997) The Ecology of Interfaces: Riparian Zones. Annual Review of Ecology and Systematics, 28, 621-658.

https://doi.org/10.1146/annurev.ecolsys.28.1.621

[2] Walling, D.E., Webb, B.W. and Russell, M.A. (1997) Sediment-Associated Nutrient Transport in UK Rivers. IAHS Publications-Series of Proceedings and Reports-Intern Assoc Hydrological Sciences, 243, 69-84.

[3] Stanford, J.A. and Ward, J.V. (1979) Stream Regulation in North America. In: Ward, J.V. and Stanford, J.A., Eds., The Ecology of Regulated Streams, Springer, Boston, MA, 215-236. https://doi.org/10.1007/978-1-4684-8613-1_13

[4] Hupp, C.R. and Simon, A. (1991) Bank Accretion and the Development of Vegetated Depositional Surfaces along Modified Alluvial Channels. Geomorphology, 4, 111-124. https://doi.org/10.1016/0169-555X(91)90023-4

[5] Tsujimoto, T. (1999) Fluvial Processes in Streams with Vegetation. Journal of Hydraulic Research, 37, 789-803. https://doi.org/10.1080/00221689909498512

[6] Toda, Y., Ikeda, S., Kumagai, K. and Asano, T. (2005) Effects of Flood Flow on Flood Plain Soil and Riparian Vegetation in a Gravel River. Journal of Hydraulic Engineering, 131, 950-960. https://doi.org/10.1061/(ASCE)0733-9429(2005)131:11(950)

[7] Darby, S.E. (1999) Effect of Riparian Vegetation on Flow Resistance and Flood Potential. Journal of Hydraulic Engineering, 125, 443-454. https://doi.org/10.1061/(ASCE)0733-9429(1999)125:5(443)

[8] Järvelä, J. (2002) Flow Resistance of Flexible and Stiff Vegetation: A Flume Study with Natural Plants. Journal of Hydrology, 269, 44-54. https://doi.org/10.1016/S0022-1694(02)00193-2

[9] Tsujimoto, T., Okada, T. and Murase, T. (1993) Vegetation and River-Morphological Characteristics in a River in Fluvial Fan. Proceedings of Hydraulic Engineering, San Francisco, 25-30 July 1993, 207-214.

[10] Ikeda, S. and Izumi, N. (1990) Width and Depth of Self-Formed Straight Gravel Rivers with Bank Vegetation. Water Resources Research, 26, 2353-2364. https://doi.org/10.1029/WR026i010p02353 
[11] Thorne, C.R. (1990) Effects of Vegetation on Riverbank Erosion and Stability. In: Thornes, J.B., Ed., Vegetation and Erosion, Wiley, Chichester, England, 125-144.

[12] Pollen, N., Simon, A. and Collison, A. (2004) Advances in Assessing the Mechanical and Hydrologic Effects of Riparian Vegetation on Streambank Stability. Riparian Vegetation and Fluvial Geomorphology, 8, 125-139. https://doi.org/10.1029/008WSA10

[13] Bayley, P.B. and Sparks, R.E. (1989) The Flood Pulse Concept in River-Floodplain Systems. Canadian Journal of Fisheries and Aquatic Sciences, 106, 110-127.

[14] Poff, N.L., Allan, J.D., Bain, M.B., Karr, J.R., Prestegaard, K.L., Richter, B.D., Sparks, R.E. and Stromberg, J.C. (1997) The Natural Flow Regime. BioScience, 47, 769-784. https://doi.org/10.2307/1313099

[15] Stevaux, J.C., Corradini, F.A. and Aquino, S. (2013) Connectivity Processes and Riparian Vegetation of the Upper Paraná River, Brazil. Journal of South American Earth Sciences, 46, 113-121. https://doi.org/10.1016/j.jsames.2011.12.007

[16] Ye, F., Chen, Q., Blanckaert, K. and Ma, J. (2013) Riparian Vegetation Dynamics: Insight Provided by a Process-Based Model, a Statistical Model and field Data. Ecohydrology, 6, 567-585. https://doi.org/10.1002/eco.1348

[17] Neiff, J.J. and Poi de Neiff, A.S.G. (2003) Connectivity Processes as a Basis for the Management of Aquatic Plants. In: Editors: Thomaz, S.M. and Bini, L.M., Eds., Ecologia e Manejo de Macrófitas Aquaticas, 1st Edition, University Estadual de Maringá, Paraná, 39-58.

[18] Shafroth, P.B., Auble, G.T., Stromberg, J.C. and Patten, D.T. (1998) Establishment of Woody Riparian Vegetation in Relation to Annual Patterns of Streamflow, Bill Williams River, Arizona. Wetlands, 18, 577-590. https://doi.org/10.1007/BF03161674

[19] Thorne, C.R. (1990) Effects of Vegetation on Riverbank Erosion and Stability. In: Thornes, J.B., Ed., Vegetation and Erosion, Wiley, Chichester, England, 125-144.

[20] Raven, P.H., Evert, R.F. and Eichhorn, S.E. (2005) Biology of Plants. Macmillan Publishers Ltd, London, England.

[21] Brookes, C.J., Hooke, J.M. and Mant, J. (2000) Modelling Vegetation Interactions with Channel Flow in River Valleys of the Mediterranean Region. Catena, 40, 93-118. https://doi.org/10.1016/S0341-8162(99)00065-X

[22] Ishikawa, S. (1991) Floodplain Vegetation of the Ibi River in Central Japan, 2: Vegetation Dynamics on the Bars in the River Course of the Alluvial Fan. Japanese Journal of Ecology, 41, 31-43.

[23] Gurnell, A.M., Petts, G.E., Hannah, D.M., Smith, B.P., Edwards, P.J., Kollmann, J., Ward, J.V. and Tockner, K. (2001) Riparian Vegetation and Island Formation along the Gravel-Bed Fiume Tagliamento, Italy. Earth Surface Processes and Landforms, 26, 31-62. https://doi.org/10.1002/1096-9837(200101)26:1<31::AID-ESP155>3.0.CO;2-Y

[24] Honkavaara, E., Saari, H., Kaivosoja, J., Pölönen, I., Hakala, T., Litkey, P., Mäkynen, J. and Pesonen, L. (2013) Processing and Assessment of Spectrometric, Stereoscopic Imagery Collected Using a Lightweight UAV Spectral Camera for Precision Agriculture. Remote Sensing, 5, 5006-5039. https://doi.org/10.3390/rs5105006

[25] Tamminga, A.D., Eaton, B.C. and Hugenholtz, C.H. (2015) UAS-Based Remote Sensing of Fluvial Change Following an Extreme Flood Event. Earth Surface Processes and Landforms, 40, 1464-1476. https://doi.org/10.1002/esp.3728

[26] Bornette, G., Henry, C., Barrat, M.H. and Amoros, C. (1994) Theoretical Habitat 
Templets, Species Traits, and Species Richness: Aquatic Macrophytes in the Upper Rhône River and its Floodplain. Freshwater Biology, 31, 487-505. https://doi.org/10.1111/j.1365-2427.1994.tb01753.x

[27] Westaway, R.M., Lane, S.N. and Hicks, D.M. (2000) The Development of an Automated Correction Procedure for Digital Photogrammetry for the Study of Wide, Shallow, Gravel-Bed Rivers. Earth Surface Processes and Landforms, 25, 209-226. https://doi.org/10.1002/(SICI)1096-9837(200002)25:2<209::AID-ESP84>3.0.CO;2-Z

[28] Johns, B., Chesher, T.J. and Soulsby, R.L. (1990) The Modelling of Sandwave Evolution Resulting from Suspended and Bed Load Transport of Sediment. Journal of Hydraulic Research, 28, 355-374. https://doi.org/10.1080/00221689009499075

[29] Kostaschuk, R., Shugar, D., Best, J.L., Parsons, D.R., Lane, S.N., Hardy, R.J. and Orfeo, O. (2008) Suspended Sediment Transport over a Dune. Conference: Marine Sand-Wave and River Dune Dynamics III, Leeds, 1-3 April 2008, 197-201.

[30] Amlin, N.M. and Rood, S.B. (2002) Comparative Tolerances of Riparian Willows and Cottonwoods to Water-Table Decline. Wetlands, 22, 338-346. https://doi.org/10.1672/0277-5212(2002)022[0338:CTORWA]2.0.CO;2

[31] Carter Johnson, W. (2000) Tree Recruitment and Survival in Rivers: Influence of Hydrological Processes. Hydrological Processes, 14, 3051-3074. https://doi.org/10.1002/1099-1085(200011/12)14:16/17<3051::AID-HYP134>3.0.CO ;2-1

[32] Rood, S.B. and Mahoney, J.M. (2000) Revised Instream Flow Regulation Enables Cottonwood Recruitment along the St. Mary River, Alberta, Canada. Rivers, 7, 109-125.

[33] Change Analysis and Control Method of River Vegetation Focused on Natural Disturbance and Artificial Influence. Ph.D. Thesis, Kyoto University, Kyoto. http://hdl.handle.net/2433/77989

[34] Casanova, M.T. and Brock, M.A. (2000) How Do Depth, Duration and Frequency of Flooding Influence the Establishment of Wetland Plant Communities? Plant Ecology, 147, 237-250. https://doi.org/10.1023/A:1009875226637 